\title{
Study on EEOI Influencing factors of large Bulk Carrier
}

\author{
LU Changyu, a, LI Wei ${ }^{2, b}$ \\ ${ }^{1}$ Navigation College, Dalian Maritime University, Dalian 116026, China \\ ${ }^{2}$ Navigation College, Dalian Maritime University, Dalian 116026, China \\ a1437823869@qq.com, b2467366218@qq.com
}

\begin{abstract}
Keywords: EEOI, Bulk carrier, Operational efficiency, Speed.
Abstract. In order to explore how large bulk carriers can reduce the operational energy efficiency index of ships and improve the operational efficiency of ships, in order to respond to the increasingly stringent emission regulations put forward by IMO and reduce the EEOI value of ships. 7,000 tons of Panamax bulk carriers are selected for shipment, and EEOI's Based on the mathematical model, the effects of speed, voyage, and cargo volume on the ship's EEOI were calculated. The results showed that the speed change had the greatest impact on the EEOI value, followed by the change in the cargo volume and the smallest change in the voyage. Reducing the workload of the host to reduce the speed of the ship and increasing the cargo carrying capacity of the ship can effectively reduce the EEOI value of the ship, while increasing the voyage will have no obvious effect on reducing the EEOI value.
\end{abstract}

\section{Introduction}

In recent years, the greenhouse effect has become more and more serious. The issue of marine exhaust emissions has caused more and more countries and social organizations to pay attention to it. At the same time, the shipping industry is also facing greater and greater challenges. In 2011, the IMO mandated the implementation of an energy efficiency index---Energy Efficiency Operation Indicator(EEOI). The index represents the environmental cost $\left(\mathrm{CO}_{2}\right.$ emissions $)$ generated by the social benefits (cargo volume) created per unit of ship transportation, EEOI= $\mathrm{M}_{\mathrm{CO}_{2}} /$ voyage, as an indicator to assess the greenhouse gas emission levels of ships. ${ }^{[1]}$ At present, there are two main directions for the study of the index: one is based on statistical analysis of actual operational data, and the other is based on theoretical analysis to establish a ship energy efficiency operation model, through the hull, propeller, host, drive system modeling Model, calculation of the discharge of ship $\mathrm{CO}_{2} \cdot{ }^{[2]}$

\section{EEOI mathematical model}

EEOI is the ratio of $\mathrm{CO}_{2}$ discharged from the ship's unit transport operations, that is, the ratio of the sum of the $\mathrm{CO}_{2}$ discharged from fuel consumption to the number of goods/persons and the transport distance. It is used to measure the level of energy efficiency of ship operations during the phase period. The definition of EEOI for a voyage is defined as follows in accordance with the Guidelines for the Voluntary Use of the Ship Energy Efficiency Operation Index (EEOI). ${ }^{[3]}$

$$
\text { EEO I }=\frac{\sum_{j} F C_{j} * C_{F_{j}}}{m_{c \text { argo }} * D}
$$

In the formula: $\mathrm{D}$ is the distance of the ship's transport cargo (n mile); ${ }^{F C_{j}}$ is the total fuel consumption of the ship during the entire voyage(t); $\mathrm{j}$ represents the fuel type; $C_{F j}$ represents the $\mathrm{CO}_{2}$ emission factor, Refers to the mass of fuel discharged per ton of fuel consumed $\mathrm{t}\left(\mathrm{CO}_{2}\right) / \mathrm{t}$ (fuel). The calculation result of formula (1) only represents one flight segment. In order to obtain the energy efficiency operation index of the entire voyage and introduce the segment variable $i$, the calculation formula of the energy efficiency operation index for the entire voyage can be obtained.

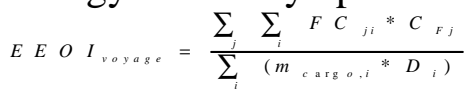

Due to the different carrying capacity of different segments, the introduction of the cargo factor $\mathrm{R}$ is defined as follows: 


$$
R=\frac{m_{c \arg o}}{D W_{d}}
$$

Then Bring into type (2)

$$
\text { EE O } I_{\text {vo o a se }}=\frac{\sum_{j} \sum_{i} F C_{j i}^{*} C_{F i}}{D W_{i} \sum\left(R_{i}{ }^{*} D_{i}\right)}
$$

Among them: $D W_{d}$ is the design load of the ship(t); $R_{i}$ is the cargo rate of the segment $\mathrm{i}$; the fuel consumption of the ship during navigation is mainly concentrated on the main engine, auxiliary engine and boiler, and the proportion of total fuel consumption is $86 \%, 10 \%, 3 \%$, you can rewrite(4)as: EEO I $I_{\text {voyage }}=\frac{\sum_{i} \sum_{i}\left(F C_{M, j i} * C_{F M E}+F C_{\mathrm{F}, j i} * C_{F F E}+F C_{\mathrm{G}, j i} * C_{F G E}\right.}{D W_{d} \sum_{i}\left(R_{i} * D_{i}\right)}$

In the formula: $F C_{M, j i}$ is the fuel consumption of the main engine of segment $\mathrm{i} ;(\mathrm{t}){ }_{F C_{\mathrm{F}, j i}}$ is the fuel consumption of the auxiliary engine of segment $\mathrm{i} ; F C_{G, j i}$ is the fuel consumption of the boiler of segment i(t) ; $C_{F M E}, C_{F F E}, C_{F G E}$ representing the emission factors of fuel $\mathrm{CO}_{2}$ consumed by the main engine, auxiliary engine and boiler. The fuel consumption of the main engine can be expressed as: $F C_{M}=P_{M} * S F C_{M} * T_{M}$

Where: $P_{M}$ is the host power $(\mathrm{Kw}) ; S F C_{M}$ represents the fuel consumption rate of the main engine $(\mathrm{kg} /(\mathrm{kWh})) ; T_{M}$ is the working time of the main engine(h), Bring (6) to (5) ${ }^{[5]}$ : EEO I voyage $_{\text {va }}=\frac{\sum_{j} \sum_{i}\left(P_{M, j i} * S F C_{M, j i} \mathrm{~T}_{M, j i} \mathrm{C}_{F M E}+F C_{F, j i} * C_{F F E}+F C_{G, j i} * C_{F G E}\right.}{1000 * D W_{d} \sum_{i}\left(R_{i} * D_{i}\right)}$

During the period of time when the vessel is in port, the ship's auxiliary engine and boiler are also working, and the ship's auxiliary engine and boiler work are the sum of the sailing time and the port time. Formula (7) can be further simplified to: EEOI $I_{\text {voyage }}=\frac{\sum_{j} \sum_{i}\left(P_{M, j i} * S F C_{M, j i} \mathrm{~T}_{M, j i} \mathrm{C}_{F M E}+F C_{F, j i} * C_{F F E}+F C_{G, j i} * C_{F G E}\right.}{1000 * D W_{d} \sum\left(R_{i} * D_{i}\right)}$

Where: $P_{M} 、 P_{F} 、 P_{G}$ representing the power of the main engine、 auxiliary engine and boiler (kw); $S F C_{M} 、 S F C_{\mathrm{F}} 、 S F C_{\mathrm{G}}$ representing the fuel consumption rate of the main engine a auxiliary engine and boiler $(\mathrm{kg} / \mathrm{kWh}) ; t_{p}$ represents the time of arrival of the ship(h); $V_{s}$ is ship speed $(\mathrm{kn})$.

\section{analysis of Bulk carrier EEOI}

EEOI is a comprehensive data, which is influenced by many factors. These influencing factors can be attributed to two types: One is the ship's own data, including but not limited to the ship's main engine, auxiliary engine, boiler fuel consumption, and all kinds of fuel's $\mathrm{CO}_{2}$ Emission factor; the other is the ship's operating data and ship design load, ship cargo load, and voyage. Using the formula (8) for EEOI simulation of bulk carriers, This paper selects a Panamanian bulk carrier, ${ }^{[7]}$ whose data is shown in table 1 .

Table 1. Main parameters of a bulk carrier

\begin{tabular}{cc}
\hline Troject & value \\
\hline Gross tonnage/t & 70000 \\
\hline Deadweight tonnage & 69967 \\
General/m & 225.0 \\
Draft/t & 13.6 \\
Speed/kn & 16.0 \\
Deep B/m & 18.7 \\
Type D/m wide & 32.2 \\
The host model & MAN B\&W 6S60MC \\
Main engine speed/RPM & 90 \\
Deputy machine & WARTSILA VASA 4R22/26 \\
The boiler model & AQ12/AQ-2 \\
\hline
\end{tabular}


The target ship design speed is $16.0 \mathrm{kn}$, equipped with one main engine, the maximum power is $9021 \mathrm{KW}$, equipped with 3 auxiliary engines, the maximum power is $600 \mathrm{KW}$, and equipped 2 boilers. impact of speed on EEOI

In the transport operations of ships, the average fuel consumption for each voyage is $99 \%$, and light oil consumption accounts for $1 \%$. Therefore, assuming that the ship uses HFO fuel for the entire voyage, the emissions of $\mathrm{CO}_{2}$ are all based on $\mathrm{HFO}$ calculations. The data show that $\mathrm{CO}_{2}$ emission factor of HFO is $3.1144 .{ }^{[7]}$ Select the target ship's voyage $\mathrm{D}=2647 \mathrm{n}$ mile, assuming that the target vessel is docked at the departure port and the terminal port, and only the heavy fuel oil is consumed for the entire voyage of the vessel (calculate the $\mathrm{CO}_{2}$ emission based on $\mathrm{HFO}$ ), and the environmental impact factors are the value and loading factor $\mathrm{R}$ take $1,0.8,0.6$, and 0.4 respectively. When the main engine load changes from $100 \%$ to $50 \%$, the ship speed is reduced from $15.99 \mathrm{kn}$ to $11.51 \mathrm{kn}$, and the EEOI of the ship is calculated using formula (8). Variable method to discuss the relationship between ship $V_{s}$ and EEOI, See Figure 1 for details.

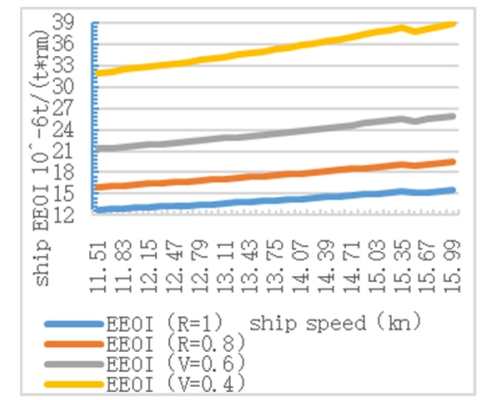

Figure 1. Relationship between $V_{s}$ and EEOI

Through figure 1. analysis, when the abscissa is constant value, namely the host load, must be ship to keep the same speed, load factor $\mathrm{R} 1$, when the minimum value EEOI, $\mathrm{R}$ in 0.4 EEOI value maximum, that under the same speed, cargo capacity EEOI value is smaller, the greater the ship's energy efficiency is higher. When ship loading factor must be district $\mathrm{R}=1$, as the host of the ship power gradually decreases, the speed from the original $15.99 \mathrm{kn} 11.51 \mathrm{kn}$, bulk EEOI as speed reduction from the original $15.99 * 10^{-6} \mathrm{t} /(\mathrm{t} * \mathrm{~nm})$ to $12.78 * 10^{-6} \mathrm{t} /(\mathrm{t} * \mathrm{~nm})$. The trend of the four curves is consistent, which fully shows that the EEOI of bulk cargo ships gradually decreases with the decrease of ship speed, and the speed is positively correlated with the height of EEOI.

\section{Impact of voyage on EEOI}

Assuming that the target ship's host is operating at $100 \%$ load, the speed is constant, ie, the speed does not change. The loading factor $\mathrm{R}$ respectively takes $1,0.8,0.6$, and 0.4 , and passes through a voyage of $\mathrm{D}=6000 \mathrm{nmile}$. The EEOI value of the segment is calculated as EEOI changes with voyage as shown in Figure 2.

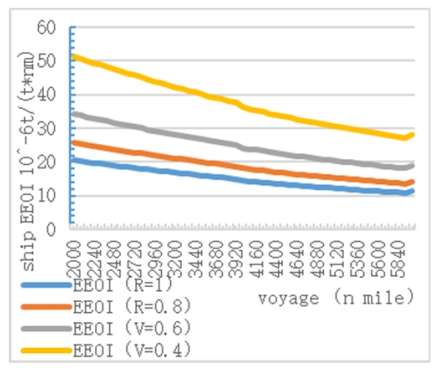

Figure 2 Relationship between voyage and EEOI

Analysis of the above figure, when the abscissa is a fixed value, that is, when the ship's voyage is fixed, the value of EEOI when the loading factor $\mathrm{R}=1$ is the smallest, and the value of the EEOI when $\mathrm{R}=0.4$ is the largest. In the same section of the voyage, the larger the loading volume is. The smaller the EEOI value, the higher the ship's energy efficiency. When the loading factor of the ship is selected, the loading factor $\mathrm{R}=1$ is selected for analysis. As the voyage of the ship increases, when the voyage is gradually increased from 2000-6000nmile, the EEOI of the bulk carrier is from the original $20.57^{*} 10^{\wedge}-6 \mathrm{t}(\mathrm{t} * \mathrm{~nm})$ drops to $11.32 * 10^{\wedge}-6 \mathrm{t}\left(\mathrm{t}^{*} \mathrm{~nm}\right)$. The trend of the four curves is consistent, which fully shows that the EEOI of the bulk carrier gradually decreases with the increase of the ship's voyage, and the voyage shows a negative correlation with the EEOI. 


\section{Effect of Cargo Volume on EEOI}

Set the voyage $\mathrm{D}=5000 \mathrm{n}$ mile, when the host load is $100 \%, 80 \%, 60 \%, 40 \%$ respectively. Under different load conditions, adjust the load factor $\mathrm{R}$ and observe the change of EEOI, as shown in Figure 3. Shown.

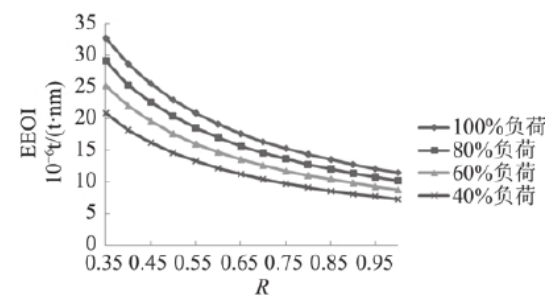

Figure 3 Relationship between cargo loading rate and EEOI

Compared with the analysis of the four curves, when the abscissa is constant, the cargo loading rate remains the same, and the ship's carrying capacity is constant. The EEOI values of the main engines operating at $100 \%, 80 \%, 60 \%$, and $40 \%$ load respectively decrease in turn. It shows that as the ship speed decreases, the ship's EEOI value gradually decreases, which is consistent with the analysis in Figure 1. The trend of the four curves is consistent. With the increase of the carrying capacity, the ship's EEOI value gradually decreases, and the carrying volume has a negative correlation with the EEOI. When the cargo loading rate increases from 0.35 to 1 , the ship's EEOI value is significantly reduced. Therefore, increasing the ship loading rate, ie increasing the cargo volume, has a significant effect on reducing the ship's EEOI, and this measure is also in line with the economic interests of shipping companies.

\section{Comparison of Impact on EEOI by Speed, Load, and Range}

In order to compare the impact of speed, cargo capacity, and voyage on the EROI, set the target large bulk carrier speed to $V_{s}=15 \mathrm{kn}$, the voyage to $\mathrm{D}=5000 \mathrm{n}$ mile, and the load volume $\mathrm{R}=70 \%$ of the standard operating status. Single-factor sensitivity analysis method, set the first two parameters unchanged, the other parameter in the initial state of $-30 \%-+30 \%$ change, every $5 \%$ simulation to get a EEOI value, and calculate it with EEOI The initial value of the rate of change, drawing the sensitivity curve shown in Figure 4.

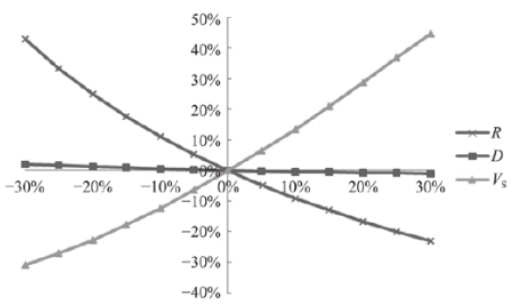

Fig. 4 EEOI sensitivity analysis of speed, payload and voyage

By comparing the effects of three operational parameters on EEOI, it can be concluded that the rate of change of EEOI is very small when the voyage is changed from $-30 \%$ to $+30 \%$, and the value of EEOI is small and almost unchanged. EEOI Sensitivity to voyage changes is low; when the volume of cargo varies between $-30 \%$ and $+30 \%$, the rate of change of EEOI is greater, the value of EEOI increases and decreases, and the sensitivity of EEOI to changes in the volume of shipments. Higher; when the speed varies between $-30 \%$ and $+30 \%$, the rate of change of EEOI is the largest, and the value of EEOI increases and decreases the most, indicating that EEOI has the highest sensitivity to changes in the volume of cargo carried. Therefore, increasing the voyage has no obvious effect on reducing the EEOI value, but reducing the speed and increasing the cargo volume is an effective means to increase the energy efficiency of ships and reduce the value of EEOI. Reducing speed, reducing fuel consumption, increasing cargo capacity, and improving transportation efficiency are both in line with environmental benefits and in line with the economic interests of shipping companies.

\section{Conclusion}

This paper establishes the mathematical calculation model of EEOI, calculates the relationship between speed, voyage, load and EEOI, and calculates the simulation results. The change of speed 
has the greatest impact on the EEOI value, and it has a positive correlation. The change of the cargo volume is followed by the change of the voyage. By reducing the speed of the main engine of the ship to reduce the speed, increasing the voyage is a measure to effectively reduce the EEOI of the ship. It is still very necessary for large bulk carriers to plan the best route, not only to consider the economy but also to consider safety. Bulk carriers play an important role in global trade. Reducing the carbon emissions of ships is of great significance to the environment. The following points are based on the actual operation of the shipping industry and put forward several feasible suggestions for reducing emissions: 1) Using shore power; 2 ) Use of high-quality marine fuels and research and development of new fuels; 3) Increase the level of ship transportation organization and management; 4) Improve the full-load rate of ships; 5) Enhance the performance of emission reduction equipment and develop new emission reduction equipment is also effective in reducing EEOI of ships. The way it focuses on improving the following aspects: exhaust gas circulation system, waste heat recovery system, air lubrication system.

\section{Acknowledgements}

This work is supported in part by the National Natural Science Foundation of China (Nos.51179019, 61374114), the Fundamental Research Program for Key Laboratory of the Education Department of Liaoning Province(LZ2015006), the Natural Science Foundation of Liaoning (20170540098), and the Fundamental Research Funds for the Central Universities under Grants 3132017115.

\section{References}

[1]LI KE-shun,LIU Yi-fan, SUN Pei-ting. Modeling and simulation of ship energy efficiency operation indicator [J]. Navigation of China,2014,02:105-108,121.

[2] SHI WEI, STAPEBSMA D, GBIMMELIUS H. Simulation of the influence of ship voyage profiles on air emissions [C] Proceed-ings of ASME International Mechanical Engineering Congress and Exposition. Boston, Massachusetts, 2008, 14:165-174

[3] MEPC 59/Circ. 684. Guidelines for voluntary use of the ship energy efficiency operational indicator (EEOI) [R]. London: IMO, 2009. 8.

[4] International Maritime Organization. Prevention of air pollution from ships, second IMO GHG study 2009[R]. London: IMO, 2009

[5] Zhou Ke, Chen Hui, Guan Cong etc. Simulation study on energy efficiency operation index of large container. Wu Han University of Technology. [J] Ship science and technology 2017(11):169174

[6] http://www.shipxy.com/

[7]NI Jun-kai. Research on ship energy efficiency operational indicator [D]. Shanghai: Shanghai Jiao Tong University, 2010. 